\title{
Tobacco mosaic virus (TMV) Replicase and Movement Protein Function Synergistically in Facilitating TMV Spread by Lateral Diffusion in the Plasmodesmal Desmotubule of Nicotiana benthamiana
}

\author{
Dana Guenoune-Gelbart, ${ }^{1}$ Michael Elbaum, ${ }^{2}$ Guy Sagi, ${ }^{1}$ Amit Levy, ${ }^{1}$ and Bernard L. Epel ${ }^{1}$ \\ ${ }^{1}$ Department of Plant Sciences, Tel Aviv University Tel Aviv, Israel; ${ }^{2}$ Department of Materials and Interfaces, Weizmann \\ Institute, Rehovot, Israel
}

Submitted 2 May 2007. Accepted 13 November 2007.

\begin{abstract}
Virus spread through plasmodesmata (Pd) is mediated by virus-encoded movement proteins (MPs) that modify Pd structure and function. The MP of Tobacco mosaic virus $\left({ }^{\mathrm{TMV}} \mathrm{MP}\right)$ is an endoplasmic reticulum (ER) integral membrane protein that binds viral RNA (vRNA), forming a vRNA:MP:ER complex. It has been hypothesized that ${ }^{T M V}$ MP causes Pd to dilate, thus potentiating a cytoskeletal mediated sliding of the vRNA:MP:ER complex through Pd; in the absence of MP, by contrast, the ER cannot move through Pd. An alternate model proposes that cell-to-cell spread takes place by diffusion of the MP:vRNA complex in the ER membranes which traverse Pd. To test these models, we measured the effect of ${ }^{\mathrm{TMV}} \mathrm{MP}$ and replicase expression on cell-to-cell spread of several green fluorescent protein-fused probes: a soluble cytoplasmic protein, two ER lumen proteins, and two ER membrane-bound proteins. Our data support the diffusion model in which a complex that includes ER-embedded MP, vRNA, and other components diffuses in the ER membrane within the Pd driven by the concentration gradient between an infected cell and adjacent noninfected cells. The data also suggest that the virus replicase and MP function together in altering Pd conductivity.
\end{abstract}

To cause disease, a virus must be capable of replicating in host cells, moving into surrounding cells, and then progressing systemically throughout the plant. It is generally accepted that plant viruses traverse the cell wall through plasmodesmata (Pd), membrane-bound tunnels that interconnect the cytoplasm of neighboring cells (Heinlein and Epel 2004). Current models of Pd structure describe a simple unbranched $\mathrm{Pd}$ as a wallembedded plasmalemma-lined cylinder that contains a central axial membrane component, termed appressed endoplasmic reticulum or desmotubule $\left(\mathrm{ER}^{\mathrm{DT}}\right)$, which is derived from and

Corresponding author: Bernard L. Epel; E-mail: blepel@ post.tau.ac.il

Nucleotide sequence data is available in the GenBank database under the following accession numbers: calreticulin (At1g56340), calnexin (At5g07340), and ACA2 (At4g37640).

* The $\boldsymbol{e}$-Xtra logo stands for "electronic extra" and indicates additional information is available online. Figure 1 appears in color and a supplementary appendix is published online. continuous with cortical endoplasmic reticulum (ER). The plasma membrane $(\mathrm{PM})$ and $\mathrm{ER}^{\mathrm{DT}}$ define a cytoplasmic sleeve that bridges the cytoplasm of contiguous cells (Heinlein and Epel 2004). The cell wall encasing Pd is modified and apparently plays a role in regulating Pd conductivity (Heinlein and Epel 2004).

The size selectivity of Pd usually is measured in terms of their molecular size exclusion limit (SEL) (Ding et al. 1999). Because the SEL for cytoplasmic spread by diffusion through $\mathrm{Pd}$ is much smaller than any known plant virus or viral genome, it generally is considered that virus cell-to-cell spread is an active or facilitated process. For many viruses, cell-tocell spread is mediated by one or more viral gene products termed movement proteins (MPs). In the absence of MP, most viruses are unable to spread cell to cell (Lucas 2006). The MP of Tobacco mosaic virus $\left({ }^{\mathrm{TMV}} \mathrm{MP}\right)$ and many other plant viruses have been shown to be ER membrane (ER ${ }^{\mathrm{mem}}$ ) proteins (Brill et al. 2000; Haupt et al. 2005; Ju et al. 2005; Reichel and Beachy 1998; Waigmann et al. 2004). The MP of TMV, which has its $\mathrm{N}$ - and C-terminus exposed to the cytoplasm (Brill et al. 2000; Reichel and Beachy 1998), binds single-stranded RNA in vitro, forming a protein:RNA complex with a thin and elongated appearance (Citovsky et al. 1992). It has been proposed that ${ }^{\mathrm{TMV}} \mathrm{MP}$ chaperones viral RNA (vRNA) through dilated Pd (Citovsky et al. 1992) as an RNAprotein complex or as a membrane complex that also includes vRNA and replicase (Asurmendi et al. 2004; Kawakami et al. 2004; Szecsi et al. 1999). To achieve viral cell-cell spread, MP in some way modifies Pd. Presumably it increases the SEL of Pd (Asurmendi et al. 2004; Deom et al. 1987; Kotlizky et al. 2001; Waigmann et al. 1994, 2004; Wolf et al. 1989) by an as yet unknown mechanism.

Although it is clear that not all viral MPs function similarly, several common features are emerging. Viral MPs can target to Pd autonomously in transgenic plants that express MP genes (Atkins et al. 1991; Kotlizky et al. 2001; Schmitz et al. 1997). Many MPs are ER associated (Haupt et al. 2005; Huang and Zhang 1999; Itaya et al. 1998; Ju et al. 2005; Kawakami et al. 1999; Krishnamurthy et al. 2003; Mitra et al. 2003; Morozov and Solovyev 2003; Padgett et al. 1996; Reichel and Beachy 1998; Waigmann et al. 2004) and bind nucleic acids in vitro (Citovsky et al. 1992; Isogai et al. 2006; Leshchiner et al. 2006), leading to the suggestion that MPs form nucleoprotein complexes with viral genomes to facilitate cell-to-cell move- 
ment. Furthermore, MP expression promotes callose degradation (Bucher et al. 2001; Fridborg et al. 2003; Iglesias and Meins 2000); thus, it has been suggested that changes in the wallsleeve surrounding Pd may be of physiological significance and may be involved in potentiating viral spread (Bucher et al. 2001; Fridborg et al. 2003; Heinlein and Epel 2004; Iglesias and Meins 2000, Levy et al. 2007).

A model has been proposed for TMV cell-to-cell spread, termed here the "ER sliding model" (Fig. 1), which hypothesizes that, upon TMV infection, newly synthesized MP inserts into ER and binds newly replicated positive-strand vRNA, forming a membrane-associated complex which also may include viral replicase. Furthermore, it is hypothesized that MP directly or indirectly changes wall properties surrounding $\mathrm{Pd}$, thus allowing the $\mathrm{Pd}$ to dilate. The dilation potentiates a cytoskeletal-mediated transport of ER or ER-derived vesicles with associated MP:vRNA cargo through Pd (Boevink and Oparka 2005; Kawakami et al. 2004; Liu et al. 2005; Wright et al. 2007). In the absence of MP, the ER in $P d$ (the $E R^{\mathrm{DT}}$ ) is

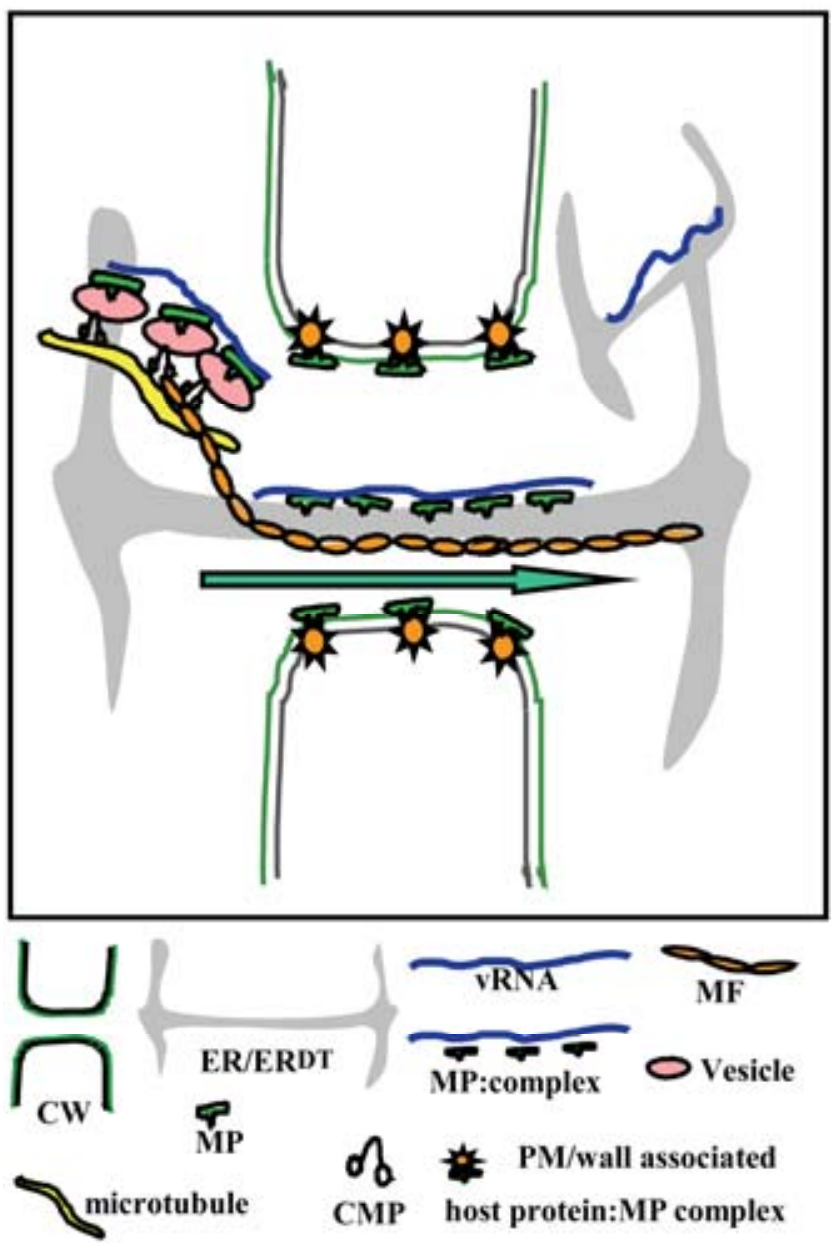

Fig. 1. Endoplasmic reticulum (ER)-sliding model of plant viral movement. According to this model, the movement protein of Tobacco mosaic virus $\left({ }^{\mathrm{TMV}} \mathrm{MP}\right)$ is an integral ER membrane $\left(\mathrm{ER}^{\mathrm{mem}}\right)$ protein (Reichel and Beachy 1998) that binds viral RNA (vRNA) (Citovsky et al. 1990, 1992). ${ }^{\mathrm{TMV}} \mathrm{MP}$ also associates with a plasmodesmata-plasma membrane (Pd-PM) wall factor causing the Pd cytoplasmic sleeve to expand (Wolf et al. 1989). Myosin or microtubule motors transport a vRNP complex to Pd-appressed ER or desmotubule (ER ${ }^{\mathrm{DT}}$ ) (Kawakami et al. 2004; Liu et al. 2005). Due to dilatation of $\mathrm{Pd}, \mathrm{ER}^{\mathrm{DT}}$ is no longer immobile and actin filaments mediate the sliding of the ER through Pd (arrow); in the absence of MP, the $\mathrm{ER}^{\mathrm{DT}}$ is stationary (i.e., does not move through the Pd). Figure is modified from Figure 4 in Heinlein and Epel (2004). MF = microfilament and CMP = cytoskeleton motor protein. stationary (Heinlein and Epel 2004). Alternatively, because MP is embedded in ER, one must consider a model in which cell-to-cell spread occurs by diffusion of an MP:vRNA complex in the lipid matrix of the $\mathrm{ER}^{\mathrm{DT}}$ under the influence of a concentration gradient between adjacent infected and uninfected cells (Lippincott-Schwartz et al. 2000; Runions et al. 2006; Saxton and Jacobson 1997).

In order to test these two models, we transiently expressed a cytoplasmic probe, green fluorescent protein (GFP) ${ }^{\text {cyt; }}$, two ER lumen $\left(\mathrm{ER}^{\mathrm{lum}}\right)$ proteins; ER lumen-retained GFP (GFP $\left.{ }^{\mathrm{ERlum}}\right)$ and calreticulin ([GFP:calreticulin $]^{\text {ERlum }}$ ) (Michalak et al. 1992); and two $\mathrm{ER}^{\text {mem }}$ proteins, ACA2 ([ACA2:GFP] ${ }^{\text {ERmem }}$ ) (Hong et al. 1999) and calnexin ([calnexin:GFP] ${ }^{\mathrm{ERmem}}$ ) (Bergeron et al. 1994; Runions et al. 2006), each fused to GFP as reporter probes (Fig. 2) in wild-type (WT) or transgenic Nicotiana benthamiana plants expressing the ${ }^{\mathrm{TMV}} \mathrm{MP}\left(\mathrm{MP}^{+}\right.$plants). The spread of probes to adjacent cells was followed by confocal laser scanning microscopy in either the absence or presence of a TMV mutant, $\mathrm{TMV}^{\triangle \mathrm{MP} \triangle \mathrm{CP}}$, which expresses only the viral replicase. GFP ${ }^{\mathrm{ER} l u m}$, a soluble GFP derivative, and calreticulin are proteins that reside in the ER lumen due to an N-terminus signaling sequence and an HDEL ER-retention signal at its C-terminus. Calreticulin binds to misfolded ER luminal proteins and prevents them from being exported from the ER to the Golgi apparatus, functioning as a quality-control chaperone. ACA2 is a multipass ER transmembrane protein with its $\mathrm{N}$ terminal side in the lumen of the ER and is a calmodulin-regulated $\mathrm{Ca}^{2+}$-ATPases shown by Hong and associates (1999) to be an intrinsic ER ${ }^{\mathrm{mem}}$ protein in Arabidopsis root cells. Calnexin is a $60-\mathrm{kDa}$ nonglycosylated type I integral protein of the ER. It consists of a large N-terminal calcium-binding lumenal domain, a single transmembrane helix, and a short cytoplasmic tail. Two probes of different size and function were chosen for each of the two ER compartments to assure that the data are not a consequence of the particular probe employed.

The ER sliding model predicts that, in the presence of MP, the cytoplasmic and membrane-protein probes should exhibit enhanced cell-to-cell spread. Our data do not support the sliding model because these predictions were not born out. However, the data do support the diffusion model, showing that the ER membrane probes do diffuse cell-to-cell. Furthermore, our data suggest that the virus replicase functions in altering $\mathrm{Pd}$ conductivity.

\section{RESULTS}

In order to test the working models, we measured the cellto-cell spread of the cytoplasmic probe GFP ${ }^{\text {cyt }}$, which accumulates as a soluble protein in the cytoplasm and nucleus; two ER lumenal protein-probes, GFP ${ }^{\text {ERlum }}$ and [GFP:calreticulin] ${ }^{\text {ERlum; }}$ and two intrinsic ER membranal protein probes, [calnexin: GFP] ${ }^{\text {ERmem }}$ and [ACA2:GFP] ${ }^{\text {ERmem }}$ (Figs. 2 and 3A through E, respectively). All probes were expressed following agroinfiltration at very low titers in $\mathrm{WT}$ and $\mathrm{MP}^{+} N$. benthamiana plants. Probe spread was measured at 48 (data not shown) and $72 \mathrm{~h}$ post-agroinfiltration (hpai) (Fig. 4, columns 1 and 3).

The percentage of infection sites that exhibit probe spread (ISEPS) of the various probes from a single infected site to neighboring cells was quantified at 72 hpai (Fig. 5). Similar results were obtained at 48 hpai. In both $\mathrm{WT}$ and $\mathrm{MP}^{+}$plants, GFP $^{\text {cyt }}$ spreads cell to cell from $100 \%$ of transfected leaf epidermal cells (Fig. 5). The extent of spread from an infected cell $(n=300)$ decreased $(P<0.05)$ from 17.7 surrounding epidermal cells in WT plants to 12.7 surrounding epidermal cells in $\mathrm{MP}^{+}$plants.

In WT plants, the spread of both $\mathrm{ER}^{\text {lum }}$ protein probes to surrounding cells was detectable in only $10 \%$ of transfected leaf 
epidermal cells (Fig. 5). In contrast, in $\mathrm{MP}^{+}$plants, the lumen probes spread from an average of $80 \%$ of transfected leaf epidermal cells (Fig. 5). These results suggest that, in $90 \%$ of WT cells, the $\mathrm{ER}^{\mathrm{DT}}$ lumen is functionally closed to diffusional transport of molecules in the size range employed via the ERlumen whereas, in transgenic plants expressing ${ }^{\mathrm{TMV}} \mathrm{MP}$, the $\mathrm{ER}^{\mathrm{DT}}$, is in some manner functionally modified, thus allowing the $\mathrm{ER}^{\text {lum }}$ probes to spread cell to cell.

In WT plants, the $\mathrm{ER}^{\mathrm{mem}}$ protein probes spread cell to cell from $80 \%$ of transfected leaf epidermal cells, demonstrating that $\mathrm{ER}^{\mathrm{mem}}$ proteins can spread cell to cell in WT noninfected cells. In contrast, in $\mathrm{MP}^{+}$plants, cell-to-cell spread was significantly reduced, occurring in only $23 \%$ of transfected leaf epidermal cells (Fig. 5). These results suggest that, in the absence of replicase (see below), ${ }^{\mathrm{TMV}} \mathrm{MP}$ expression inhibits cell-to-cell spread of $\mathrm{ER}^{\mathrm{mem}}$ proteins.

In order to test for the effect of active viral replication on probe spread in WT and $\mathrm{MP}^{+}$plants, each probe was coexpressed together with the TMV ${ }^{\triangle \mathrm{MP} \Delta \mathrm{CP}}$, a TMV mutant lacking both MP and coat protein $(\mathrm{CP})$ that expresses only the TMV replicase (Fig. 2). The probes were expressed by agroinfiltration employing low titers of Agrobacterium while TMV ${ }^{\triangle \mathrm{MP} \Delta \mathrm{CP}}$ was coexpressed employing a 750-fold higher titer of Agrobacterium. Cell-to-cell spread of each probe was assayed (Figs. 4, columns 2 and 4, and 5).

In WT plants, the fraction of infection sites exhibiting spread of $\mathrm{GFP}^{\text {cyt }}$ and of both $\mathrm{ER}^{\mathrm{mem}}$ probes from the expressing cell to surrounding cells was significantly reduced $(P<0.05)$ upon expression of the mutant virus TMV $\triangle \mathrm{MP} \Delta \mathrm{CP}$ (Fig. 5). Moreover, in those cells exhibiting spread $(n=300)$, the extent of GFP $^{\text {cyt }}$ spread decreased from an average of 17.7 to 2.9 cells $(P<0.05)$. In contrast, the extent of spread of both $\mathrm{ER}^{\mathrm{mem}}$ probes in those infection sites exhibiting cell-to-cell spread was essentially unaffected.

In $\mathrm{MP}^{+}$plants, $\mathrm{TMV}^{\triangle \mathrm{MP} \triangle \mathrm{CP}}$ is complemented and the mutant virus spreads cell to cell, producing necrotic lesions on $N$. tabacum cv. Xanthi NN leaves (data not shown). In $\mathrm{MP}^{+}$plants, the expression of $\mathrm{TMV}^{\triangle \mathrm{MP} \Delta \mathrm{CP}}$ significantly increased $(P<0.05)$ the fraction of infection sites exhibiting cell-to-cell spread of $\mathrm{ER}^{\mathrm{mem}}$ probes approximately three- to fourfold (Fig. 5). Al-
GFPcyt: cytoplasmic
enhanced GFP

[GFP] ${ }^{\text {ERlum : ER lumen }}$ soluble GFP with a Nterminus signaling peptide and a HDEL ER-retention signal at C-terminus

[GFP:Calreticulin] ERlum : ER lumen soluble protein with a N-terminus signaling peptide and a HDEL ERretention signal at $\mathrm{C}$-terminus

[Calnexin:GFP]ERmem : ER type I membrane protein with a $\mathrm{N}$-terminus signaling peptide
$27 \mathrm{kDa}$

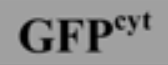

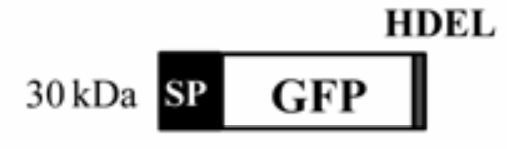

\section{[ACA2:GFP] ${ }_{\text {ERmem : }}$
calmodulin regulated $\mathrm{CA}^{2+}$ -
ATPase ERmem protein \\ [ACA2:GFP] $\mathbf{E R m e m :}$
calmodulin regulated $\mathrm{CA}^{2+}$ -
ATPase ERmem protein \\ [ACA2:GFP] $\mathbf{E R m e m :}$
calmodulin regulated $\mathrm{CA}^{2+}$ -
ATPase ERmem protein}

TMV $\Delta$ MP $\Delta$ CP : RNA of TMV mutant lacking both MP and CP expressing only TMV replicase
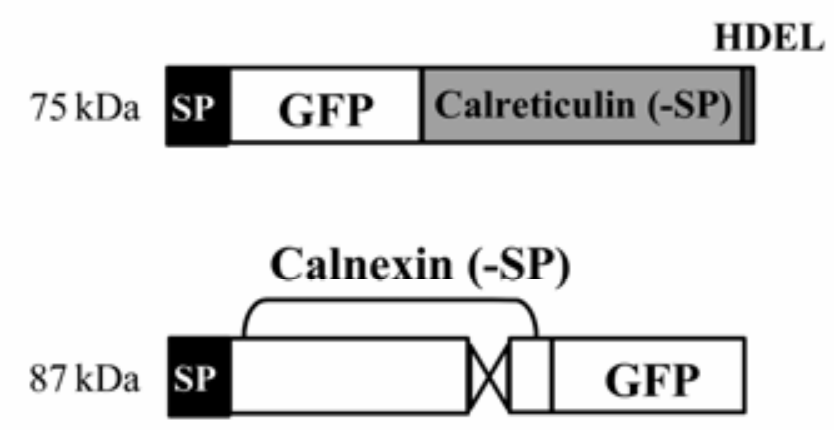
though the expression of $\mathrm{TMV}^{\triangle \mathrm{MP} \Delta \mathrm{CP}}$ in $\mathrm{MP}^{+}$plants had no effect on the number of sites from which GFP ${ }^{\text {cyt }}$ spread $(100 \%)$, the extent of GFP $^{\text {cyt }}$ spread $(P<0.05)$ increased from 12.7 surrounding epidermal cells in noninfected $\mathrm{MP}^{+}$plants to 18.2 surrounding cells in $\mathrm{MP}^{+}$plants expressing $\mathrm{TMV}^{\Delta \mathrm{MP} \Delta \mathrm{CP}}$

In both $\mathrm{WT}$ and $\mathrm{MP}^{+}$plants, callose accumulation around $\mathrm{Pd}$ significantly increased as a result of agroinfiltration (wound- ing) (Fig. 6A and B). In WT plants, TMV ${ }^{\Delta \mathrm{MP} \Delta \mathrm{CP}}$ expression further induced $\mathrm{Pd}$-associated callose accumulation while the coexpression of $\mathrm{TMV}^{\triangle \mathrm{MP} \triangle \mathrm{CP}}$ and ${ }^{\mathrm{TMV}} \mathrm{MP}$ resulted in a significant reduction in callose accumulation, even compared with nonwounded plants (Fig. 6A and B). These results suggest that, in the presence of ${ }^{\mathrm{TMV}} \mathrm{MP}$, the expression of $\mathrm{TMV}^{\triangle \mathrm{MP} \Delta \mathrm{CP}}$ lowers the levels of $\mathrm{TMV}^{\triangle \mathrm{MP} \Delta \mathrm{CP}}$ stress-induced callose.
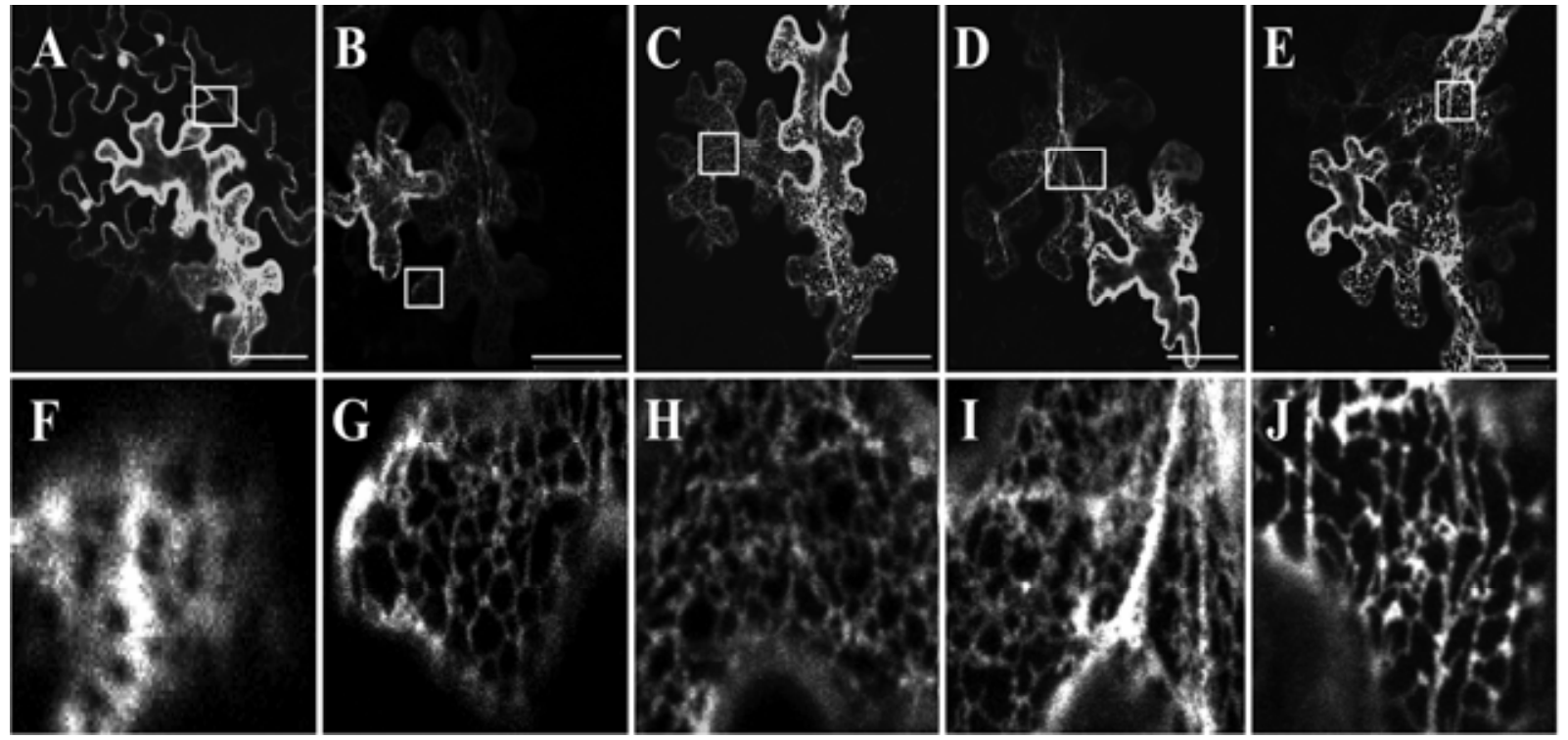

Fig. 3. Subcellular localization of cytoplasmic enhanced green fluorescent protein $\left(\mathrm{GFP}^{\mathrm{cyt}}\right)$ and endoplasmic reticulum lumen and membrane $\left(\mathrm{ER}^{\mathrm{lum}}\right.$ and $\mathrm{ER}^{\mathrm{mem}}$, respectively) proteins. Confocal micrograph showing localization of the GFP fusion proteins after Agrobacterium infiltration. A, GFP ${ }^{\mathrm{cyt}}$ localizes to cytoplasm and nucleus; B, GFP ${ }^{\text {ERlum }} ; \mathbf{C}$, [GFP:Calreticulin] ${ }^{\text {ERlum}} ; \mathbf{D}$, [Calnexin:GFP] ${ }^{\text {ERmem }}$; and E, [ACA2:GFP] ${ }^{\text {ERmem }}$, all localize to ER in both initially infected cell and adjacent cells into which probe has spread. F through J, Enlargements of the areas inside the boxes in A-E, respectively. Bar, $50 \mu \mathrm{m}$.

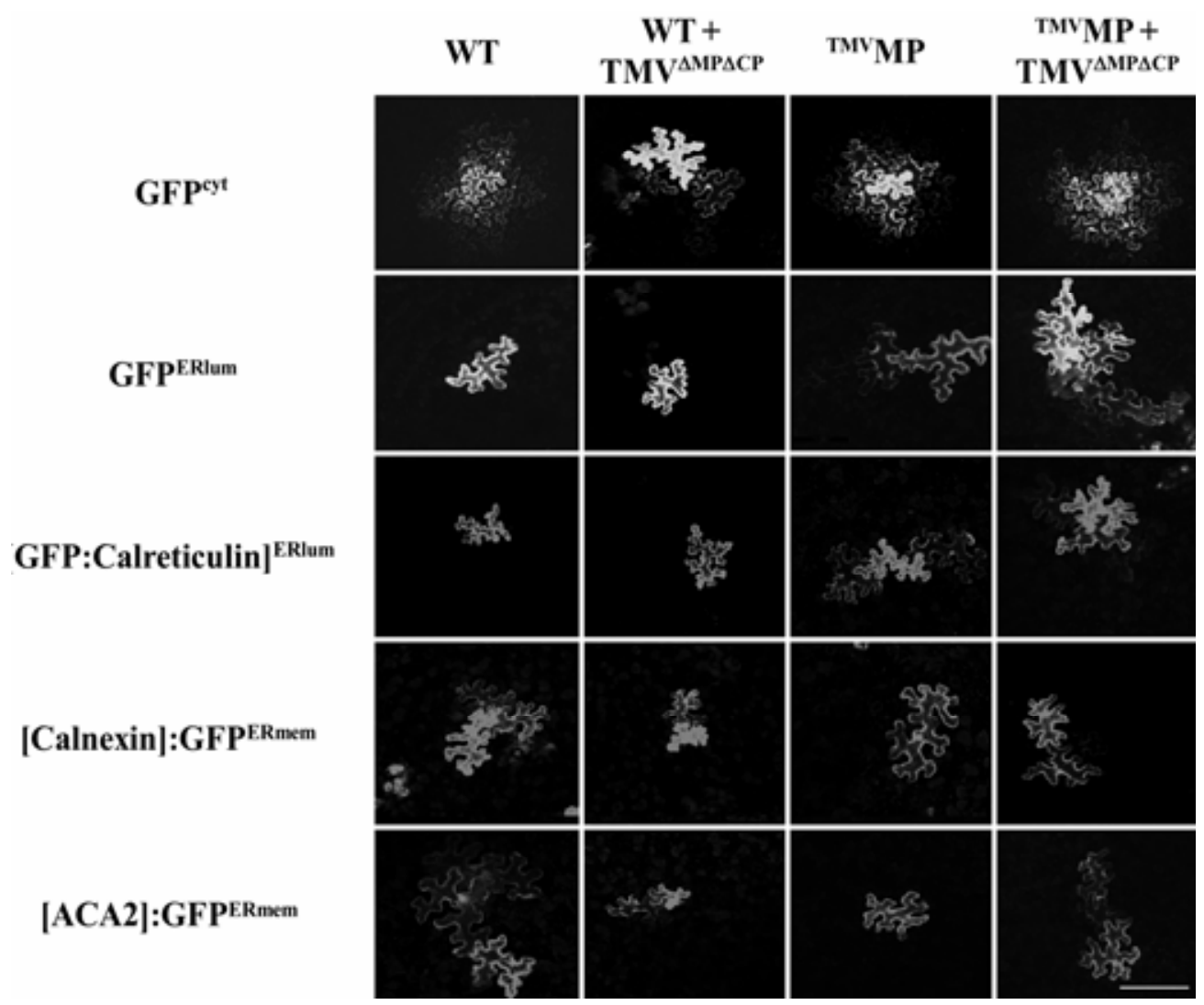

Fig. 4. Confocal micrographs showing examples of cell-to-cell spread of cytoplasmic enhanced green fluorescent protein (GFP ${ }^{\mathrm{cyt}}$ ) and endoplasmic reticulum lumen and membrane (ER ${ }^{\text {lum }}$ and $\mathrm{ER}^{\mathrm{mem}}$, respectively) probes in epidermal cells of wild-type (WT) and movement protein-expressing (MP $\left.{ }^{+}\right)$plants in the absence or presence of mutant Tobacco mosaic virus (TMV) ${ }^{\Delta \mathrm{MP} \Delta \mathrm{CP}}$. Bar, $50 \mu \mathrm{m}$. 


\section{DISCUSSION}

Most plant viruses spread from cell to cell by a mechanism involving an interaction between MP, virus, and Pd. In the case of TMV, the MP inserts into ER membrane (Boevink and Oparka 2005; Brill et al. 2000; Reichel and Beachy 1998) and binds vRNA (Citovsky et al. 1992), forming an endomembrane:MP:vRNA-complex (Kawakami et al. 2004) that also sequesters replicase, forming a replication complex (Heinlein et al. 1998; Liu et al. 2005; Nelson and Citovsky 2005; Reichel and Beachy 1998; Waigmann et al. 2004). Furthermore, because ER is continuous through Pd, it was suggested that vRNA cellto-cell spread occurs in association with this membrane compartment (Boevink and Oparka 2005; Mas and Beachy 1999; Nelson and Citovsky 2005; Reichel and Beachy 1998; Szecsi et al. 1999).

The colocalization of MP with ER or ER-derived vesicles and with microtubules (Heinlein et al. 1995) and microfilaments (McLean et al. 1995) led to the suggestion that cytoskeletal elements are involved in Pd targeting and cell-to-cell movement of the viral ribonucleoprotein complex (Heinlein et al. 1995; Mitra et al. 2003). Moreover, because MP purportedly dilated $\mathrm{Pd}$, and because highly mobile ER and ER-derived vesicles are closely associated with actin filaments (Quader et al. 1987), its was postulated that motility is along actin cables, possibly using myosin or other motor proteins that link the ER to cytoskeleton (Heinlein and Epel 2004; Knebel et al. 1990). Moreover, because actin and myosin are present inside the Pd (Blackman and Overall 1998), it was suggested that, as a result of the MP-induced dilation of Pd, the ER or ER-derived vesicles with the bound MP:vRNA:protein complex now could be transported by microfilament-driven transport, an active process, through the dilated Pd (Boevink and Oparka 2005; Gillespie et al. 2002; Heinlein and Epel 2004; Reichel et al. 1999). It has been estimated that the intracellular movement of viral vesicles on the cytoskeleton in primary infected cells is approximately $160 \mathrm{~nm} / \mathrm{s}$ (Kawakami et al. 2004). At this rate, if the viral vesicles were to continue moving on the cytoskeleton through a dilated Pd, spread would be on the order of seconds. Such rapid spread is not detected; the movement of a viral replication complex from the first infection site to the second can be detected within $20 \mathrm{~h}$, and from the second infection site to adjacent cells within $4 \mathrm{~h}$ (Kawakami et al. 2004). Similar results were obtained in the absence of virus infection (Kotlizky et al. $2001)$, in which spread of ${ }^{\mathrm{TMV}} \mathrm{MP}$ fused to GFP $\left({ }^{\mathrm{TMV}} \mathrm{MP}: \mathrm{GFP}\right)$

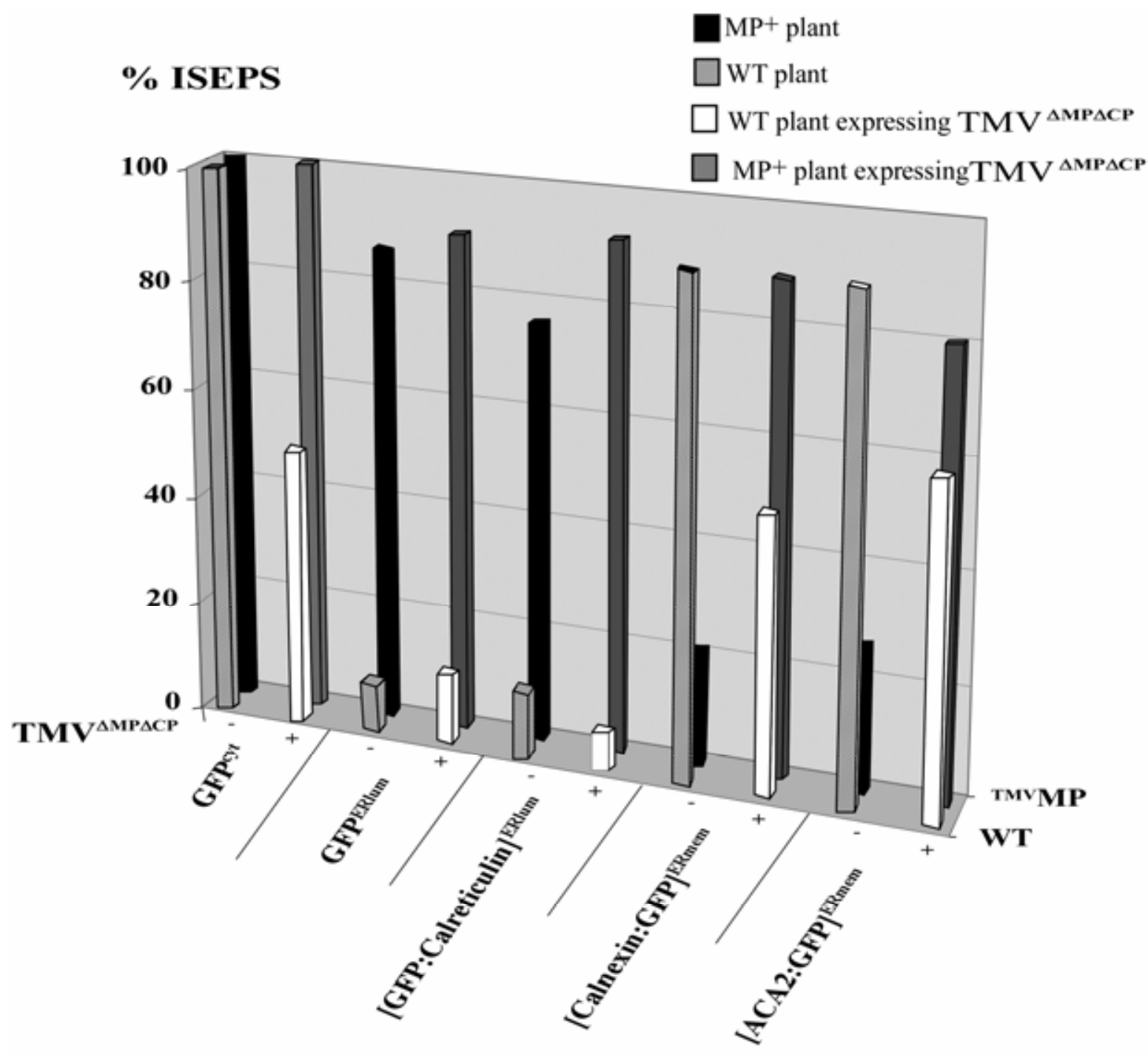

Fig. 5. Spread of cytoplasmic enhanced green fluorescent protein $\left(G^{2} P^{c y t}\right)$ and endoplasmic reticulum lumen and membrane (ER ${ }^{\text {lum }}$ and ER $\left.^{\text {mem }}\right)$ probes from a source cell to adjacent cells of wild-type (WT) and movement protein-expressing ( $\mathrm{MP}^{+}$) plants in the absence or presence of mutant Tobacco mosaic virus $(\mathrm{TMV})^{\triangle \mathrm{MP} \Delta \mathrm{CP}}$. The infection sites exhibiting probe spread (ISEPS) is reported as the percentage of transfected cells that allow spread of probes into adjacent cells in the absence $(-)$ and presence $(+)$ of TMV $\mathrm{TMP}^{\triangle \mathrm{CP}}$ as determined by confocal laser scanning microscopy. 
spread was detected at approximately $24 \mathrm{~h}$ postbombardment, although subsequent spread was more rapid.

The data presented here do not fit the sliding-ER model. The expression of MP did not stimulate cell-to-cell spread of either GFP $^{\text {cyt }}$ (Fig. 5) (Liarzi and Epel 2005) or either of the $\mathrm{ER}^{\mathrm{mem}}$ probes as predicted by the sliding model but, rather, inhibited spread (Fig. 5). The time course of the cell-to-cell movement of the $\mathrm{ER}^{\mathrm{mem}}$ probes observed in the present work is similar to that observed for virus spread; therefore, we suggest that the
MP:vRNP complex moves slowly by obstructed diffusion in the lipid membrane of the $\mathrm{ER}^{\mathrm{DT}}$ to the Pd. The faster viral spread time of approximately $4 \mathrm{~h}$ that was obtained following inoculation of a single $N$. clevelandii trichome with Tobacco rattle virus (Derrick et al. 1992) may be due to differences in tissue and the nature and number of Pd in trichomes (Waigmann et al. 1997). The finding that MP expression inhibits spread of cytoplasmic soluble probes is in agreement with Storms and associates (1998), who reported a decrease of Pd SEL after
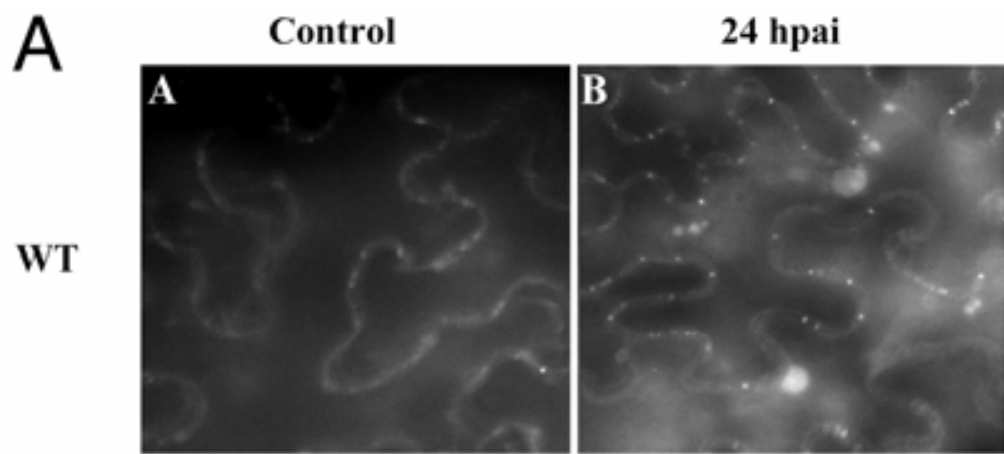

\section{4 hpai:TMV $\triangle M P \triangle C P$}
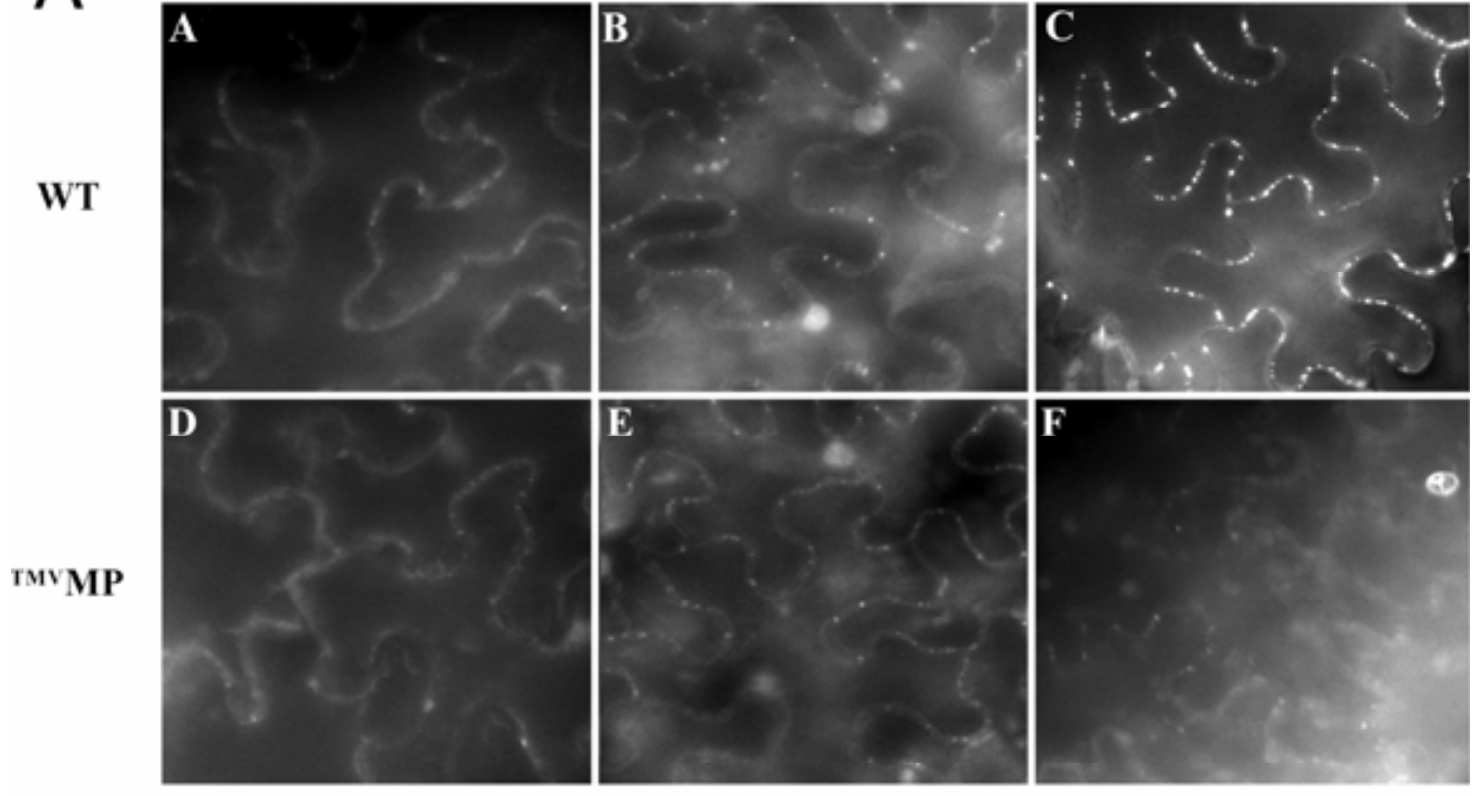
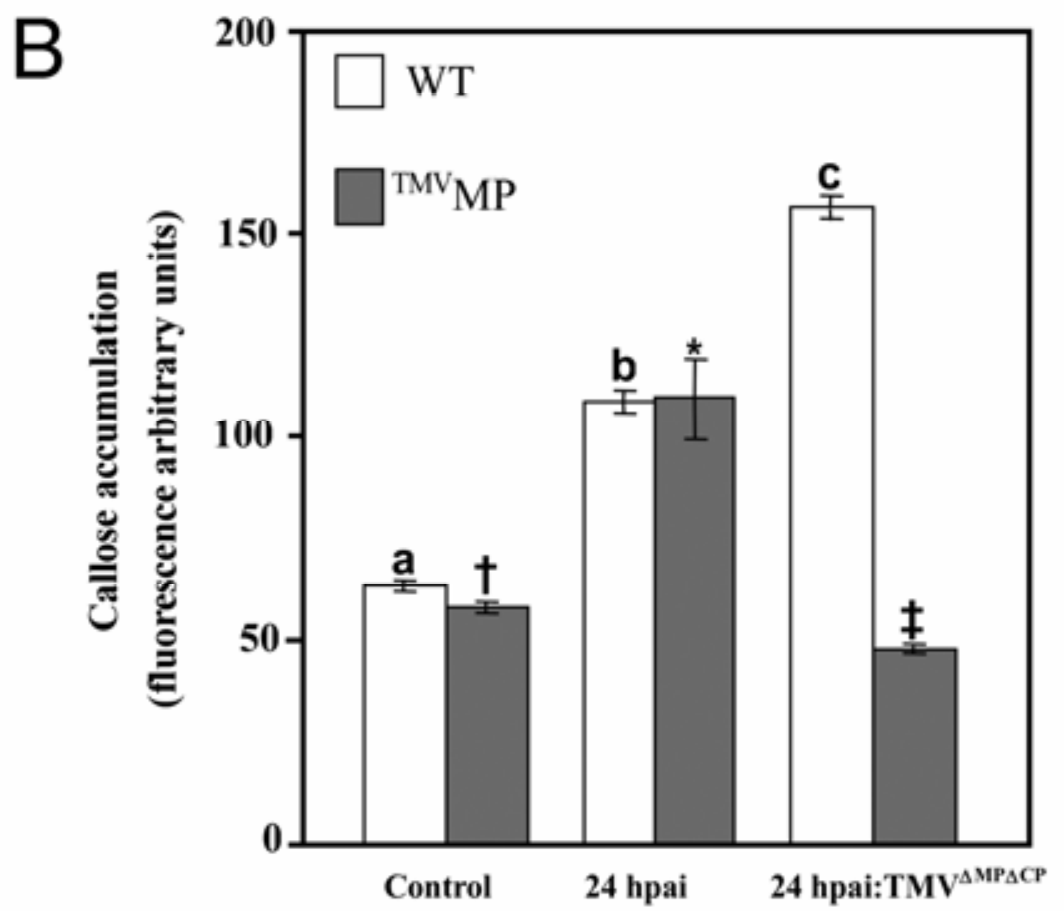

Fig. 6. Callose accumulation in wild-type (WT) and movement protein-expressing (MP ${ }^{+}$) plants in response to wounding (agroinfiltration) and to mutant Tobacco mosaic virus (TMV) ${ }^{\triangle \mathrm{MP} \Delta \mathrm{CP}}$ transient expression. A, Fluorescent micrographs of epidermal cells stained with aniline blue of WT (sections A through C) and $\mathrm{MP}^{+}$(D through F) plants: A and D, control cells without treatment; B and E, 24 h post-agroinfiltration (hpai) of Agrobacteria containing a blank cassette or $\mathrm{C}$ and F, expressing TMV ${ }^{\triangle \mathrm{MP}} \Delta \mathrm{CP}$. B, Leaves of WT and $\mathrm{MP}^{+}$plants that were leaf-injected with Agrobacteria containing a blank cassette or express-

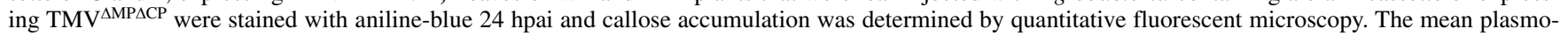
desmata callose intensity was expressed in arbitrary units as mean intensity \pm standard error of the mean of three independent experiments. Different letters designate significantly different values at $P<5 \%$, as measured by means and $t$ test. 
iontophoretic microinjection of transgenic plants expressing TSWV or TMV MP. This is in contrast to other reports employing various MPs in which fluorescent probes were introduced by a pressure injection technique and which reported that MP increased Pd SEL (Deom et al. 1987, 1990; Ding et al. 1992; Storms et al. 1998; Wolf et al. 1989; 1991). These latter studies reported a SEL of less than $1 \mathrm{kDa}$ in the absence of MP and that MP gated Pd to allow macromolecules $>1 \mathrm{kDa}$ to spread cell to cell. Recent alternate studies now show that Pd do conduct macromolecules in the absence of MP (Crawford and Zambryski 2001; Liarzi and Epel 2005; Martens et al. 2006; Oparka and Cruz 2000; Oparka et al. 1999).

Our data suggest that MP expression functionally alters $\mathrm{ER}^{\mathrm{DT}}$ conductivity, potentiating spread of $\mathrm{ER}^{\mathrm{lum}}$ probes. The nature of this change is unclear. Because GFP:calreticulin ${ }^{\text {ERlum }}$, $\mathrm{GFP}^{\mathrm{ERlum}}$, and $2 \times \mathrm{GFP}^{\mathrm{ERlum}}$ (data not shown) all spread cell to
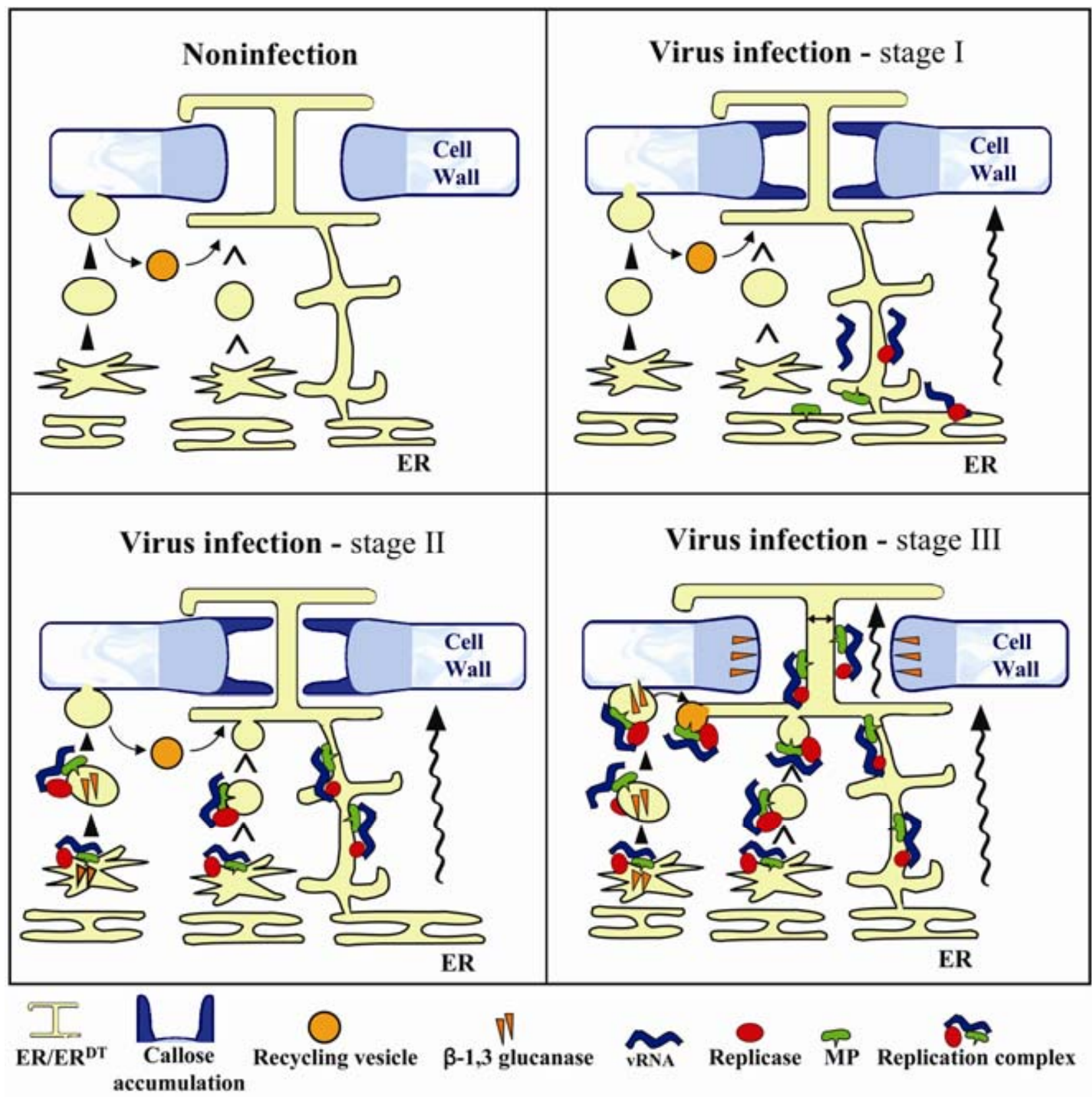

Fig. 7. Modified integrated diffusion model of Tobacco mosaic virus (TMV) cell-to-cell spread. Stage I: upon viral infection, viral RNA (vRNA) initiates synthesis of replicase with the resultant transcription of plus and minus vRNA stands and subgenomic vRNAs leading to the synthesis of replicase, movement protein (MP), and coat protein (CP) (CP is not required for virus cell spread). MP of TMV ( $\left.{ }^{\mathrm{TMV}} \mathrm{MP}\right)$ associates with the endoplasmic reticulum (ER) (Mas and Beachy 1999) as an ER membrane (ER ${ }^{\mathrm{mem}}$ ) protein (Brill et al. 2000; Reichel and Beachy 1998). In response to infection, callose accumulates in the wall region surrounding the plasmodesmata $(\mathrm{Pd})$ restricting the cytoplasmic sleeve. Stage II: the cytoplasmic exposed domain of TMV MP functions as a protein raft and binds vRNA which may complex with replicase forming an ER-virus replication complex (VRC) (Kawakami et al. 2004) which traffics by diffusion within the ER lipids to the appressed ER or desmotubule (ER ${ }^{\mathrm{DT}}$ ) (squiggle arrow) or by vesicular trafficking to the cortical ER (open arrowheads). Stress-induced class I $\beta$-1,3-glucanase accumulates in ER and traffics in lumen of VRC vesicles to plasma membrane with requisite docking protein (Fridborg et al. 2003) (filled arrowheads); vesicular trafficking is probably along actin filaments (not shown). Stage III: cycling vesicles containing $\beta$-1,3-glucanase cargo fuse to plasma membrane and deliver $\beta$-1,3-glucanase to the cell wall (filled arrowheads). Callose is hydrolyzed, allowing Pd to dilate. Vesicles with attached VRCs recycle back to the cortical ER where vesicles fuse to cortical ER (curved arrow). VRCs diffuse in ER-ER ${ }^{\text {DT }}$ continuum through the Pd to adjacent cells by diffusion (squiggle arrow) motivated by the concentration gradient in the ER continuum between a viral infected cell and adjacent noninfected cells. 
cell via the $\mathrm{ER}^{\mathrm{DT}}$ lumen in MP transgenic plants, we suggest that this cell-to-cell spread probably is not the consequence of a reported interaction between calreticulin and ${ }^{\mathrm{TMV}} \mathrm{MP}$ (Chen et al. 2005) because three different probes all were capable of spreading.

\section{ER ${ }^{\text {mem }}$ probes move cell to cell by diffusion in the $\mathbf{E R}^{\mathrm{DT}}$.}

Our data demonstrate that ER-membrane-intrinsic proteins can spread cell to cell. The ER is a fluid lipid structure in which lipids, embedded proteins, and protein complexes can move by diffusion (Lippincott-Schwartz et al. 2000; Runions et al. 2006; Saxton and Jacobson 1997). Grabski and associates (1993) showed that, in soybean root cells, lipids in the ER but not in the PM can spread cell to cell. The present data demonstrate that proteins can move by diffusion in the ER membrane from cell to cell. These data are consistent with obstructed protein diffusion in the ER-ER ${ }^{\mathrm{DT}}-\mathrm{ER}$ continuum (Saxton and Jacobson 1997). Thus, ER ${ }^{\text {mem }}$-embedded proteins, such as ER-associated MPs, if not anchored in some manner, should be capable of diffusion from cell to cell in the $\mathrm{ER}^{\mathrm{DT}}$ lipids under the influence of a diffusion gradient between cells (Lippincott-Schwartz et al. 2000; Runions et al. 2006; Saxton and Jacobson 1997). Our hypothesis that $\mathrm{ER}^{\mathrm{mem}}$ proteins diffuse cell to cell within the ER ${ }^{\mathrm{DT}}$ membrane lipid milieu is supported by the findings of Ohba and associates (2004), who showed that integral ER proteins move from the cytoplasmic ER to the inner nuclear membrane by lateral diffusion through the nuclear pore membrane. Protein diffusion rates within ER membranes also can be affected by several factors, including association with other membrane proteins, protein complexes, and aggregation (Nehls et al. 2000). The reduced rate of spread of $\mathrm{ER}^{\mathrm{mem}}$ protein probes that we observed in $\mathrm{MP}^{+}$plants may be explained by hindrance of diffusion in the ER lipids due to the presence of ${ }^{\mathrm{TMV}} \mathrm{MP}$ within the $\mathrm{ER}^{\mathrm{DT}}$ membrane (Sung and Yethiraj 2006).

A biophysical analysis of protein transport through the $\mathrm{Pd}$ in either the cytoplasm, the ER lumen, or ER membranes leads to the conclusion that cell-to-cell probe diffusion is significantly fast to explain observations (Supplementary appendix). In all cases, the estimated rates of passive diffusion across a model Pd are somewhat faster than the observed rates. Although many factors could slow the cell-to-cell spread of the probe proteins, the analysis indicates that active mechanisms are not required to explain their transport.

\section{TMV ${ }^{\triangle M P \Delta C P}$ inhibits cell-to-cell spread of GFP ${ }^{\text {cyt }}$ and $E R^{\mathrm{mem}}$ probes in WT plants and induces callose accumulation at Pd.}

The finding that, in WT plants, cell-to-cell spread of either $\mathrm{GFP}^{\text {cyt }}$ or of $\mathrm{ER}^{\mathrm{mem}}$ protein probes is significantly inhibited when infected with $T M V^{\triangle M P \Delta C P}$, suggests that, in the absence of ${ }^{\mathrm{TMV}} \mathrm{MP}$, the expression of TMV ${ }^{\triangle \mathrm{MP} \Delta \mathrm{CP}}$ induces a stress reaction, possibly callose accumulation, which inhibits cell-to-cell spread (Iglesias and Meins 2000). Our measurements of callose accumulation support this hypothesis (Fig. 6A and B). In $\mathrm{MP}^{+}$plants infected by $\mathrm{TMV}^{\triangle \mathrm{MP} \Delta \mathrm{CP}}$, the level of $\mathrm{TMV}^{\triangle \mathrm{MP} \triangle \mathrm{CP}}$ stress-induced callose around Pd (Fig. 6A and B) was lower, presumably due to increased recruitment or activity of class I $\beta$-1,3-glucanase (Iglesias and Meins 2000). The lowering of callose levels is dependent on the expression of both MP and replicase (Fig. 6A and B). Similarly, Fridborg and associates (2003) suggested that Potato virus X (PVX) infection increased callose deposition in the neck region of Pd and that TGB12K, one of the triple-gene-block proteins, increases the SEL via callose degradation promoting PVX spread. Their data suggest that the PVX MP, TGB12K, directs endomembrane derived vesicles containing class I $\beta$-1,3-glucanase, putatively a vacuo- lar enzyme (Vandenbulcke et al. 1989), to the PM, thus reducing callose accumulation and promoting PVX cell-to-cell spread (Fridborg et al. 2003).

\section{Replicase is involved and necessary for TMV cell-to-cell spread.}

Although ${ }^{\mathrm{TMV}} \mathrm{MP}$ is necessary for cell-to-cell spread of viral infection (Heinlein and Epel 2004), it is not sufficient. Our results are in accord with a previous suggestion that replicase is involved and necessary for cell-to-cell movement of TMV (Hirashima and Watanabe 2003). Our results also are in accord with the suggestion that replicase is part of a virus movement complex that contains all essential components necessary for virus replication (vRNA, replicase, and MP) (Kawakami et al. 2004).

\section{Proposed model.}

A modified integrated model of TMV cell-to-cell spread is presented in Figure 7. According to this model, during early infection, the plant cell reacts to the infection leading to callose accumulation and Pd blockage (virus infection stage I). ${ }^{\mathrm{TMV}} \mathrm{MP}$, upon synthesis, associates with (Mas and Beachy 1999) and integrates into ER (Brill et al. 2000; Reichel and Beachy 1998), and binds vRNA (Citovsky et al. 1992); replicase, it is suggested, also becomes associated with the complex (virus infection stage II) (Heinlein et al. 1998; Liu et al. 2005; Szecsi et al. 1999). This complex may traffic intracellularly to the $\mathrm{ER}^{\mathrm{DT}}$ either as vesicles (Fig. 7, open arrowhead) (Liu et al. 2005; Peremyslov et al. 1999) or by diffusion in ER membranes (Fig. 7, squiggle arrow). ER-derived vesicles probably move to Pd along actin filaments (not shown) (Kawakami et al. 2004; Liu et al. 2005; Szecsi et al. 1999). Tagami and Watanabe (2006) present data showing that the ER-Golgi secretory pathway probably is not involved in targeting VRCs to the $\mathrm{Pd}$ and in viral intercellular movement because treatment with brefeldin A, which disrupts ER-to-Golgi transport, did not inhibit the targeting of MP to Pd and viral cell-to-cell spread (Tagami and Watanabe 2006). Replicase and MP function synergistically, possibly by targeting class I $\beta$-1,3-glucanase via cycling ER-derived vesicles to the wall surrounding the Pd (Fridborg et al. 2003). In the wall domain surrounding the Pd, class I $\beta$-1,3-glucanase decreases callose accumulation around the $\mathrm{Pd}$ induced by the virus infection, thus allowing unimpeded diffusion of the MP:vRNA:replicase complex in the $\mathrm{ER}^{\mathrm{DT}}$ membrane (Fig. 7, virus infection stage III arrowhead). The model allows for intracellular but not intercellular trafficking to be mediated by cytoskeletal elements. Recent evidence favors microfilaments because viral spread is blocked by inhibitors of filamentous actin and myosin but not by inhibitors of microtubules (Gillespie et al. 2002; Kawakami et al. 2004; Liu et al. 2005). We suggest that the involvement of cytoskeletal elements is indirect, functioning in either stabilizing the ER (Heinlein et al. 1998), targeting vesicles containing $\beta$-1,3-glucanase to the wall surrounding the Pd (Fridborg et al. 2003), or possibly the intracellular trafficking of the MP:endomembrane vesicle to the region of the ER in proximity to Pd (Oparka 2004; Reichel et al. 1999).

\section{Conclusion.}

Our modified model proposes that vRNA slowly spreads through the Pd by passive diffusion as an MP:vRNA complex, possibly also associated with replicase in the lipid milieu of the $E R^{\mathrm{DT}}$ due to the concentration gradient of the MP:vRNA complex between a viral-infected cell and adjacent noninfected cells. Our data show that ER membrane proteins can move cell to cell by restricted diffusion in the ER via the $\mathrm{ER}^{\mathrm{DT}}$. Furthermore, our data and those of others show that both MP and repli- 
case are involved in preventing stress-induced callose accumulation at Pd. These data and those of others lead us to propose a modified model which posits that vRNA slowly spreads through the Pd by passive diffusion on an MP raft as an MP:vRNA complex, possibly also associated with replicase in the lipid milieu of the $\mathrm{ER}^{\mathrm{DT}}$; diffusion is driven by the concentration gradient of the MP:vRNA complex between a viral-infected cell and adjacent noninfected cells. This transport is dependent on the prevention of callose accumulation in the Pd wall sleeve mediated by the synergetic effect of MP and replicase.

\section{MATERIALS AND METHODS}

\section{Plant material.}

WT and $\mathrm{MP}^{+}$transgenic $N$. benthamiana plants (Kotlizky et al. 2001) were grown in growth chamber in $10-\mathrm{cm}$ pots in a mix of equal volumes of soil and vermiculite (Pecka Hipper Gan, Rehovot, Israel) at $25^{\circ} \mathrm{C}$ under long day conditions (cycle of $16 \mathrm{~h}$ of light and $8 \mathrm{~h}$ of darkness).

\section{Construction of plant expression plasmids.}

The plasmid pBinGFP:calreticulin (Fig. 2) was constructed in two steps by modifying the plasmid pBinGFP (Sagi et al. 2005). The GFP gene, without its stop codon, first was polymerase chain reaction (PCR) amplified with the calreticulin signal peptide employing forward primer (FP) 5'-CTCTTTGA TTCTTTTCGCTCTCGTGGTGATCGTCTCTGCTGAAATGG TGAGCAAGGGCGAGG-3' $\mathrm{FP}$ and reverse primer (RP) $5^{\prime}$ GCGGCCGCCTTGTACAGCTCGTCCATGCC-3' containing an NotI site. A second PCR was performed on the first PCR product with FP 5'-CCTAGGATGGCGAAACTAAACCCTAA ATTCATCTCTTTGATTCTTTTCGCTCTCGTG-3' containing an AvrII site and RP 5'-GCGGCCGCCTTGTACAGCTCGT CCATGCC-3' containing an NotI site. The AvrII-SP-GFP-NotI fragment was cloned into a unique $\mathrm{XbaI}$ site present in pBinGFP between the omega enhancer sequence and the GFP start codon and a unique NotI site present in pBinGFP between the GFP stop codon and the NOS terminator sequence. The AvrII-SP-GFP-NotI fragment replaced the GFP and formed a pBinSPGFP plasmid. In the second step, the calreticulin gene was PCR amplified without its signal peptide, with an FP 5'GCGGCCGCAGTTATCTTCGAGGAGAAATTCGAAGATG G-3' containing an NotI site and RP 5'-GCGGCCGCTTAGA GCTCGTCATGGGCGGCATC-3' containing an NotI site and cloned into a unique Not I site present in pBinSPGFP between the SPGFP last codon and the NOS terminator sequence. PCR was used to verify calreticulin orientation in pBinGFP:calreticulin and the calreticulin gene was amplified with FP 5'-TC TCTTTGATTCTTTTCGCTCTCGTGGTGATCGTCTCTGCT GAAATGGTGAGCAAGGGCGAGG-3' and RP 5'-GCGGCC GCTTAGAGCTCGTCATGGGCGGCATC-3'.

To construct plasmid pBincalnexin:GFP (Fig. 2), the calnexin gene was amplified without its stop codon, by PCR with FP 5'GTATCCTTAGAGTCCTAGGAATTCATGAGAGAACGGAT TATTACATTCGTTTC-3' containing AvrII and EcoRI sites and RP 5'-GTATCCTTAGAGTCCTAGGACTCTCACGCCTC GTCTGC-3' containing an AvrII site. The AvrII-EcoRI-calnexin-AvrII fragment was cloned into a unique $X b a$ I site present in pBinGFP between the omega enhancer sequence and the GFP start codon. EcoRI digestion was used to verify calnexin orientation in pBincalnexin:GFP.

\section{Construction of minimal replicon.}

The TMV-based replicon 5' 20-GFP-22 3' (Man and Epel 2004) was digested by EcoRV and NotI, the sticky end produced by NotI was blunted, and the large fragment was self ligated to produce plasmid $\mathrm{pTMV}^{\Delta \mathrm{MP} \Delta \mathrm{CP}}$. Plasmid $\mathrm{pTMV}^{\Delta \mathrm{MP} \Delta \mathrm{CP}}$ contains the TMV CDNA without nucleotides 4,927 to 6,191 cloned in pBLUESCRIPT KS(+). Plasmid pTMV ${ }^{\triangle \mathrm{MP} \Delta \mathrm{CP}}$ was digested by $S p l 1$ and $C f r 9$ I and a Spl1-Cfr9I fragment containing the deletion of MP and CP (nucleotides 4927-6191) was moved into p35SU1R (Dagless et al. 1997) digested by the same enzymes, thus replacing the Spl1-Cfr9I fragment from the complete TMV (GenBank accession no. V01408) CDNA of p35SU1R by the Spl1-Cfr9I fragment from pTMV ${ }^{\triangle \mathrm{MP} \Delta \mathrm{CP}}$ and producing p35S[TMV $\left.{ }^{\triangle \mathrm{MP} \Delta \mathrm{CP}}\right] \mathrm{R}$. The $35 \mathrm{~S}: \mathrm{TMV}^{\triangle \mathrm{MP} \Delta \mathrm{CP}}:$ :ribozyme cassette was excised from $\mathrm{p} 35 \mathrm{~S}\left[\mathrm{TMV}^{\triangle \mathrm{MP} \Delta \mathrm{CP}}\right] \mathrm{R}$ by digestion with Pst 1 and cloned into the unique Pst 1 site of pPZP222 (Hajdukiewicz

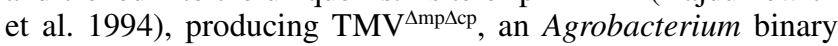
plasmid designed to express a minimal TMV replicon devoid of MP and CP sequences (Fig. 2).

\section{Transient expression.}

Transient expression was induced using Agrobacterium infiltration as previously described (Sagi et al. 2005). GFP fluorescence was examined in epidermal cells at the lower face of leaves 48 or 72 hpai. All the probes were injected with very low titers of Agrobacterium to ensure low-density-separated infection sites $\left(5 \times 10^{6} \mathrm{CFU} / \mathrm{ml}\right)$. At this titer, approximately 90\% of cells injected with Agrobacterium expressing dsRed fluorescence was detected in a single cell only 72 hpai. The TMV mutant lacking both MP and CP (TMV $\left.{ }^{\triangle \mathrm{MP} \Delta \mathrm{CP}}\right)$ was transiently expressed by agroinfiltration at a 750 -fold higher titer $\left(4 \times 10^{9} \mathrm{CFU} / \mathrm{ml}\right)$ to permit its expression in almost all epidermal cells (Man and Epel 2006). At this titer, approximately 90\% of the cells were infected by Agrobacterium expressing $\mathrm{TMV}^{\triangle \mathrm{MP} \triangle \mathrm{CP}}$ (expressing GFP under the CP subgenomic promoter) at 72 hpai.

\section{Callose staining and callose quantification.}

Callose staining was performed by immersing whole leaves for $4 \mathrm{~h}$ in $85 \%$ ethanol and then incubating leaf segments for $16 \mathrm{~h}$ in a mixture of $0.1 \%$ aniline blue (Fluka, Buchs, Switzerland) in double-distilled water and $1 \mathrm{M}$ glycine, $\mathrm{pH}=9.5$, at a volume ratio of $2: 3$, respectively.

Callose quantification was performed by measuring its aniline blue fluorescence intensity. Fluorescence was viewed with a DMRBE fluorescence light microscope (Leica, Wetzlar, Germany) employing a 340- to 380-nm band-pass excitation filter, an RKP 400 dichromatic mirror, and a long-pass 425-nm emission filter.

Analysis of fluorescence intensity associated with Pd of aniline blue was performed under nonsaturation excitation levels with the image processing software ImageJ $1.31 \mathrm{v}$ by subtracting the minimum fluorescence value in the area adjacent to the Pd (background) from the maximum fluorescent value of the Pd foci.

\section{Confocal fluorescence microscopy.}

Fluorescence microscopy was carried out using a Zeiss R510 confocal laser scanning microscope. GFP excitation was performed with an argon laser set to $488 \mathrm{~nm}$ and fluorescence detected with a 505- to 530-nm band-pass filter combination. Images were processed with Photoshop 7.0.

\section{Statistical analysis.}

All experimental values were based on at least three independent experiments with each construct for each plant line, and at least 50 replicates were conducted for each combination of construct and plant line. The cell-to-cell movement of the different plant lines was compared by analysis of variance and $t$ test analysis according to the statistical program JMP statistical software from SAS (version 4.0.0; SAS Institute Inc., Cary, NC U.S.A.). The analysis of the least significant difference 
(LSD) according to the JMP program indicates which means are different from each other at $P<0.05$.

\section{ACKNOWLEDGMENTS}

This research was supported by Resource Grant Award No IS-3222-01C from BARD, The United States-Israel Binational Agricultural Resource and Development Fund and by a post-doctor fellowship from the Manna Institute for Plant Biosciences at Tel Aviv University. We thank J. Harper for supplying $A C A 2 p$, J. Haseloff and colleagues for supplying pBinerGFP, U. Hannania and A. Avni for kindly supplying pBinGFP plasmid, and S. Shooster for technical assistance.

\section{LITERATURE CITED}

Asurmendi, S., Berg, R. H., Koo, J. C., and Beachy, R. N. 2004. Coat protein regulates formation of replication complexes during tobacco mosaic virus infection. Proc. Natl. Acad. Sci. U.S.A. 101:1415-1420.

Atkins, D., Hull, R., Wells, B., Roberts, K., Moore, P., and Beachy, R. N. 1991. The tobacco mosaic virus $30 \mathrm{~K}$ movement protein in transgenic tobacco plants is localized to plasmodesmata. J. Gen. Virol. 72:209211.

Bergeron, J. J. M., Brenner, M. B., Thomas, D. Y., and Williams, D. B. 1994. Calnexin - a membrane-bound chaperone of the endoplasmicreticulum. Trends Biochem. Sci. 19:124-128.

Blackman, L. M., and Overall, R. L. 1998. Immunolocalisation of the cytoskeleton to plasmodesmata of Chara corallina. Plant J. 14:733-741.

Boevink, P., and Oparka, K. J. 2005. Virus-host interactions during movement processes. Plant Physiol. 138:1815-1821.

Brill, L. M., Nunn, R. S., Kahn, T. W., Yeager, M., and Beachy, R. N. 2000. Recombinant Tobacco mosaic virus movement protein is an RNA-binding, alpha-helical membrane protein. Proc. Natl. Acad. Sci. U.S.A. 97:7112-7117.

Bucher, G. L., Tarina, C., Heinlein, M., Di Serio, F., Meins, F., Jr., and Iglesias, V. A. 2001. Local expression of enzymatically active class I beta-1, 3-glucanase enhances symptoms of TMV infection in tobacco. Plant J. 28:361-369.

Chen, M. H., Tian, G. W., Gafni, Y., and Citovsky, V. 2005. Effects of calreticulin on viral cell-to-cell movement. Plant Physiol. 138:1866-1876.

Citovsky, V., Knorr, D., Schuster, G., and Zambryski, P. C. 1990. The P30 movement protein of tobacco mosaic virus is a single-strand nucleic acid binding protein. Cell 60:637-647.

Citovsky, V., Wong, M. L., Shaw, A. L., Prasad, B. V., and Zambryski, P. C. 1992. Visualization and characterization of tobacco mosaic virus movement protein binding to single-stranded nucleic acids. Plant Cell 4:397-411.

Crawford, K. M., and Zambryski, P. C. 2001. Non-targeted and targeted protein movement through plasmodesmata in leaves in different developmental and physiological states. Plant Physiol. 125:1802-1812.

Dagless, E. M., Shintaku, M. H., Nelson, R. S., and Foster, G. D. 1997. A CaMV $35 \mathrm{~S}$ promoter driven cDNA clone of tobacco mosaic virus can infect host plant tissue despite being uninfectious when manually inoculated onto leaves. Arch. Virol. 142:183-191.

Deom, C. M., Oliver, M. J., and Beachy, R. N. 1987. The 30-kilodalton gene-product of tobacco mosaic-virus potentiates virus movement. Science 237:389-394.

Deom, C. M., Schubert, K. R., Wolf, S., Holt, C. A., Lucas, W. J., and Beachy, R. N. 1990. Molecular characterization and biological function of the movement protein of tobacco mosaic virus in transgenic plants. Proc. Natl. Acad. Sci. U.S.A. 87:3284-3288.

Derrick, P. M., Barker, H., and Oparka, K. J. 1992. Increase in plasmodesmatal permeability during cell-to-cell spread of tobacco rattle virus from individually inoculated cells. Plant Cell 4:1405-1412.

Ding, B., Turgeon, R., and Parthasarathy, M. V. 1992. Substructure of Freeze-Substituted Plasmodesmata. Protoplasma 169:28-41.

Ding, B., Itaya, A., and Woo, Y. M. 1999. Plasmodesmata and cell-to-cell communication in plants. Int. Rev. Cytol. 190:251-316.

Fridborg, I., Grainger, J., Page, A., Coleman, M., Findlay, K., and Angell, S. 2003. TIP, a novel host factor linking callose degradation with the cell-to-cell movement of Potato virus X. Mol. Plant-Microbe Interact. 16:132-140

Gillespie, T., Boevink, P., Haupt, S., Roberts, A. G., Toth, R., Valentine, T., Chapman, S., and Oparka, K. J. 2002. Functional analysis of a DNA-shuffled movement protein reveals that microtubules are dispensable for the cell-to-cell movement of Tobacco mosaic virus. Plant Cell 14:1207-1222.

Grabski, S., Defeijter, A. W., and Schindler, M. 1993. Endoplasmic-reticulum forms a dynamic continuum for lipid diffusion between contiguous soybean root-cells. Plant Cell 5:25-38.
Hajdukiewicz, P., Svab, Z., and Maliga, P. 1994. The small, versatile Ppzp family of Agrobacterium binary vectors for plant transformation. Plant Mol. Biol. 25:989-994.

Haupt, S., Cowan, G. H., Ziegler, A., Roberts, A. G., Oparka, K. J., and Torrance, L. 2005. Two plant-viral movement proteins traffic in the endocytic recycling pathway. Plant Cell 17:164-181.

Heinlein, M., and Epel, B. L. 2004. Macromolecular transport and signaling through plasmodesmata. Int. Rev. Cytol. Surv. Cell Biol. 235:93164.

Heinlein, M., Epel, B. L., Padgett, H. S., and Beachy, R. N. 1995. Interaction of Tobamovirus movement proteins with the plant cytoskeleton. Science 270:1983-1985.

Heinlein, M., Padgett, H. S., Gens, J. S., Pickard, B. G., Casper, S. J., Epel, B. L., and Beachy, R. N. 1998. Changing patterns of localization of the tobacco mosaic virus movement protein and replicase to the endoplasmic reticulum and microtubules during infection. Plant Cell 10:1107-1120.

Hirashima, K., and Watanabe, Y. 2003. RNA helicase domain of Tobamovirus replicase executes cell-to-cell movement possibly through collaboration with its nonconserved region. J. Virol. 77:12357-12362.

Hong, B. M., Ichida, A., Wang, Y. W., Gens, J. S., Pickard, B. C., and Harper, J. F. 1999. Identification of a calmodulin-regulated Ca2+ATPase in the endoplasmic reticulum. Plant Physiol. 119:1165-1175.

Huang, M., and Zhang, L. 1999. Association of the movement protein of alfalfa mosaic virus with the endoplasmic reticulum and its trafficking in epidermal cells of onion bulb scales. Mol. Plant-Microbe Interact. 12:680-690.

Iglesias, V. A., and Meins, F., Jr. 2000. Movement of plant viruses is delayed in a beta-1,3-glucanase-deficient mutant showing a reduced plasmodesmatal size exclusion limit and enhanced callose deposition. Plant J. 21:157-166.

Isogai, M., Watanabe, K., Uchidate, Y., and Yoshikawa, N. 2006. Proteinprotein- and protein-RNA-binding properties of the movement protein and VP25 coat protein of Apple latent spherical virus. Virology 352:178-187.

Itaya, A., Woo, Y. M., Masuta, C., Bao, Y. M., Nelson, R. S., and Ding, B. 1998. Developmental regulation of intercellular protein trafficking through plasmodesmata in tobacco leaf epidermis. Plant Physiol. 118:373385.

Ju, H. J., Samuels, T. D., Wang, Y. S., Blancaflor, E., Payton, M., Mitra, R., Krishnamurthy, K., Nelson, R. S., and Verchot-Lubicz, J. 2005. The potato virus $\mathrm{X}$ TGBp2 movement protein associates with endoplasmic reticulum-derived vesicles during virus infection. Plant Physiol. 138:1877-1895.

Kawakami, S., Padgett, H. S., Hosokawa, D., Okada, Y., Beachy, R. N., and Watanabe, Y. 1999. Phosphorylation and or presence of serine 37 in the movement protein of tomato mosaic tobamovirus is essential for intracellular localization and stability in vivo. J. Virol. 73:6831-6840.

Kawakami, S., Watanabe, Y., and Beachy, R. N. 2004. Tobacco mosaic virus infection spreads cell to cell as intact replication complexes. Proc. Natl. Acad. Sci. U.S.A. 101:6291-6296.

Knebel, W., Quader, H., and Schnepf, E. 1990. Mobile and immobile endoplasmic-reticulum in onion bulb epidermis cells-short-term and long-term observations with a confocal laser scanning microscope. Eur. J. Cell Biol. 52:328-340.

Kotlizky, G., Katz, A., vanderLaak, J., Boyko, V., Lapidot, M., Beachy, R. N., Heinlein, M., and Epel, B. L. 2001. A dysfunctional movement protein of tobacco mosaic virus interferes with targeting of wild-type movement protein to microtubules. Mol. Plant-Microbe Interact. 14:895-904.

Krishnamurthy, K., Heppler, M., Mitra, R., Blancaflor, E., Payton, M., Nelson, R. S., and Verchot-Lubicz, J. 2003. The Potato virus X TGBp3 protein associates with the ER network for virus cell-to-cell movement. Virology 309:135-151.

Leshchiner, A. D., Solovyev, A. G., Morozov, S. Y., and Kalinina, N. O. 2006. A minimal region in the NTPase/helicase domain of the TGBp1 plant virus movement protein is responsible for ATPase activity and cooperative RNA binding. J. Gen. Virol. 87:3087-3095.

Levy, A., Erlanger, M., Rosenthal, M., and Epel, B. L. 2007. A plasmodesmata-associated beta-1,3-glucanase in Arabidopsis. Plant J. 49:669-82.

Liarzi, O., and Epel, B. L. 2005. Development of a quantitative tool for measuring changes in the coefficient of conductivity of plasmodesmata induced by developmental, biotic, and abiotic signals. Protoplasma 225:67-76.

Lippincott-Schwartz, J., Roberts, T. H., and Hirschberg, K. 2000. Secretory protein trafficking and organelle dynamics in living cells. Annu. Rev. Cell Dev. Biol. 16:557-589.

Liu, J. Z., Blancaflor, E. B., and Nelson, R. S. 2005. The tobacco mosaic virus 126-kilodalton protein, a constituent of the virus replication complex, alone or within the complex aligns with and traffics along microfilaments. Plant Physiol. 138:1853-1865. 
Lucas, W. J. 2006. Plant viral movement proteins: Agents for cell-to-cell trafficking of viral genomes. Virology 344:169-184.

Man, M., and Epel, B. L. 2004. Characterization of regulatory elements within the coat protein $(\mathrm{CP})$ coding region of Tobacco mosaic virus affecting subgenomic transcription and green fluorescent protein expression from the CP subgenomic RNA promoter. J. Gen. Virol. 85:17271738.

Man, M., and Epel, B. L. 2006. Assessment of the effectiveness of a nuclear-launched TMV-Based replicon as a tool for foreign gene expression in plants in comparison to direct gene expression from a nuclear promoter. Transgenic Res. 15:107-113.

Martens, H. J., Roberts, A. G., Oparka, K. J., and Schulz, A. 2006. Quantification of plasmodesmatal endoplasmic reticulum coupling between sieve elements and companion cells using fluorescence redistribution after photobleaching. Plant Physiol. 142:471-480.

Mas, P., and Beachy, R. N. 1999. Replication of tobacco mosaic virus on endoplasmic reticulum and role of the cytoskeleton and virus movement protein in intracellular distribution of viral RNA. J. Cell Biol. 147:945958

McLean, B. G., Zupan, J., and Zambryski, P. C. 1995. Tobacco mosaic virus movement protein associates with the cytoskeleton in tobacco cells. Plant Cell 7:2101-2114

Michalak, M., Milner, R. E., Burns, K., and Opas, M. 1992. Calreticulin. Biochem. J. 285:681-692.

Mitra, R., Krishnamurthy, K., Blancaflor, E., Payton, M., Nelson, R. S. and Verchot-Lubicz, J. 2003. The Potato virus $X$ TGBp2 protein association with the endoplasmic reticulum plays a role in but is not sufficient for viral cell-to-cell movement. Virology 312:35-48.

Morozov, S. Y., and Solovyev, A. G. 2003. Triple gene block: Modular design of a multifunctional machine for plant virus movement. J. Gen. Virol. 84:1351-1366.

Nehls, S., Snapp, E. L., Cole, N. B., Zaal, K. J. M., Kenworthy, A. K., Roberts, T. H., Ellenberg, J., Presley, J. F., Siggia, E., and LippincottSchwartz, J. 2000. Dynamics and retention of misfolded proteins in native ER membranes. Nat. Cell Biol. 2:288-295.

Nelson, R. S., and Citovsky, V. 2005. Plant viruses. Invaders of cells and pirates of cellular pathways. Plant Physiol. 138:1809-1814

Ohba, T., Schirmer, E. C., Nishimoto, T., and Gerace, L. 2004. Energyand temperature-dependent transport of integral proteins to the inner nuclear membrane via the nuclear pore. J. Cell Biol. 167:1051-1062.

Oparka, K. J. 2004. Getting the message across: How do plant cells exchange macromolecular complexes? Trends Plant Sci. 9:33-41.

Oparka, K. J., and Cruz, S. S. 2000. The great escape: Phloem transport and unloading of macromolecules. Annu. Rev. Plant Physiol. Plant Mol. Biol. 51:323-347.

Oparka, K. J., Roberts, A. G., Boevink, P., Santa Cruz, S., Roberts, I., Pradel, K. S., Imlau, A., Kotlizky, G., Sauer, N., and Epel, B. 1999. Simple, but not branched, plasmodesmata allow the nonspecific trafficking of proteins in developing tobacco leaves. Cell 97:97:743-754.

Padgett, H. S., Epel, B. L., Kahn, T. W., Heinlein, M., Watanabe, Y., and Beachy, R. N. 1996. Distribution of Tobamovirus movement protein in infected cells and implications for cell-to-cell spread of infection. Plant J. 10:1079-1088.

Peremyslov, V. V., Hagiwara, Y., and Dolja, V. V. 1999. HSP70 homolog functions in cell-to-cell movement of a plant virus. Proc. Natl. Acad. Sci. U.S.A. 96:14771-14776.

Quader, H., Hofmann, A., and Schnepf, E. 1987. Circumstantial evidence for the involvement of actin in ER distribution in plant-cells. Eur. J. Cell Biol. 43:45-45

Reichel, C., and Beachy, R. N. 1998. Tobacco mosaic virus infection in- duces severe morphological changes of the endoplasmic reticulum. Proc. Natl. Acad. Sci. U.S.A. 95:11169-11174.

Reichel, C., Mas, P., and Beachy, R. N. 1999. The role of the ER and cytoskeleton in plant viral trafficking. Trends Plant Sci. 4:458-462.

Runions, J., Brach, T., Kuhner, S., and Hawes, C. 2006. Photoactivation of GFP reveals protein dynamics within the endoplasmic reticulum membrane. J. Exp. Bot. 57:43-50.

Sagi, G., Katz, A., Guenoune-Gelbart, D., and Epel, B. L. 2005. Class reversibly glycosylated polypeptides are plasmodesmal-associated proteins delivered to plasmodesmata via the Golgi apparatus. Plant Cell 17:1788-1800.

Saxton, M. J., and Jacobson, K. 1997. Single-particle tracking: Applications to membrane dynamics. Annu. Rev. Biophys. Biomol. Struct 26:373-399.

Schmitz, J., StussiGaraud, C., Tacke, E., Prufer, D., Rohde, W., and Rohfritsch, O. 1997. In situ localization of the putative movement protein (pr17) from potato leafroll luteovirus (PLRV) in infected and transgenic potato plants. Virology 235:311-322.

Storms, M. M. H., van der Schoot, C., Prins, M., Kormelink, R., van Lent, J. W. M., and Goldbach, R. W. 1998. A comparison of two methods of microinjection for assessing altered plasmodesmal gating in tissues expressing viral movement proteins. Plant J. 13:131-140.

Sung, B. J., and Yethiraj, A. 2006. Lateral diffusion and percolation in membranes. Phys. Rev. Lett. 96:228103.

Szecsi, J., Ding, X. S., Lim, C. O., Bendahmane, M., Cho, M. J., Nelson, R. S., and Beachy, R. N. 1999. Development of tobacco mosaic virus infection sites in Nicotiana benthamiana. Mol. Plant-Microbe Interact. 12:143-152.

Tagami, Y., and Watanabe, Y. 2007. Effects of brefeldin A on the localization of Tobamovirus movement protein and cell-to-cell movement of the virus. Virology 361: 133-140.

Vandenbulcke, M., Bauw, G., Castresana, C., Vanmontagu, M., and Vandekerckhove, J. 1989. Characterization of vacuolar and extracellular beta$(1,3)$-glucanases of tobacco-Evidence for a strictly compartmentalized plant defense system. Proc. Natl. Acad. Sci. U.S.A. 86:2673-2677.

Waigmann, E., Lucas, W. J., Citovsky, V., and Zambryski, P. C. 1994. Direct functional assay for tobacco mosaic virus cell-to-cell movement protein and identification of a domain involved in increasing plasmodesmal permeability. Proc. Natl. Acad. Sci. U.S.A. 91:1433-1437.

Waigmann, E., Turner, A., Peart, J., Roberts, K., and Zambryski, P. C. 1997. Ultrastructural analysis of leaf trichome plasmodesmata reveals major differences from mesophyll plasmodesmata. Planta 203:75-84.

Waigmann, E., Ueki, S., Trutnyeva, K., and Citovsky, V. 2004. The ins and outs of nondestructive cell-to-cell and systemic movement of plant viruses. Crit. Rev. Plant Sci. 23:195-250.

Wolf, S., Deom, C. M., Beachy, R. N., and Lucas, W. J. 1989. Movement protein of tobacco mosaic-virus modifies plasmodesmatal size exclusion limit. Science 246:377-379.

Wolf, S., Deom, C. M., Beachy, R., and Lucas, W. J. 1991. Plasmodesmatal function is probed using transgenic tobacco plants that express a virus movement protein. Plant Cell 3:593-604.

Wright, K. M., Wood, N. T., Roberts, A. G., Chapman, S., Boevink, P. MacKenzie, K. M., and Oparka, K. J. 2007. Targeting of TMV movement protein to plasmodesmata requires the actin/ER network: Evidence from FRAP. Traffic 8:21-31.

\section{AUTHOR-RECOMMENDED INTERNET RESOURCE}

National Institute of Health ImageJ 1.31v software: rsb.info.nih.gov/ij 